\title{
Are foods bearing health claims medicinal products?
}

\author{
By Patrick Coppens, Marlene Bijlsma, Neville Craddock, \\ Inneke Herreman, Eva Hurt, Yves Le Bail-Collet and Peter Loosen
}

\begin{abstract}
- European legislation on foods and medicine has failed to keep pace with the developments in nutrition and medical science that now recognise many important contributions that diet and individual foods may make to the promotion and maintenance of health. EU food law prevents the communication of these benefits to consumers, whilst the law on medicinal products is established on a very broad basis that also encompasses foods making preventive, therapeutic or curative claims. This legislation, together with the lack of universal definitions in food law, results in divergence and legal uncertainty within and between Member States, and is in urgent need of revision.

In this article, these aspects are investigated and illustrated by relevant case law. The legal boundaries of such concepts as "food", "medicinal products", "prevention", "disease risk reduction", etc., based on current EU legislation, national practices and case law, are explored. Finally, the concept of "Disease Risk Reduction", as proposed by various international bodies, is discussed in the light of current legislation, together with a proposal that claims for foods based on this concept should be excluded from the medical scope of the term "prevention".

It is concluded that it is necessary to set clear-cut unambiguous definitions for medicinal products and foodstuffs and to clarify in the labelling directive that reduction of disease risk claims do not fall under the prohibition of preventive claims. The recently proposed changes to the definition of medicinal products, the proposed definition of foodstuffs in the general food law regulation, and the discussion paper on health claims on European level fundamentally fail to clarify these issues.
\end{abstract}

\section{Introduction}

It is a general principle, worldwide, that in communication with consumers, no properties relating to the ability to prevent, treat or cure human diseases may be directly or indirectly attributed to individual foods. However, there is increasing evidence that a healthy diet and life-style can effectively diminish the risk of several chronic diseases. In some countries, references to a limited number of specific "preventive" effects have already been legally accepted, for example relating to the link between several chronic "Western" diseases and the consumption of fruit and vegetables and food components such as unsaturated fatty acids, dietary fibre and folic acid. The growing scientific consensus underlying such claims for foods has been thoroughly investigated by ILSI (1-3). The US Food and Drug Administration has issued a guideline paper (4) and work is also in hand within the Council of Europe (5) and the Codex Alimentarius Committee on Nutrition and Foods for Special Dietary Uses (6).

In European legislation, Directive 2000/13 (7) specifically prohibits attributing to foods any properties of preventing, treating or curing a human disease, or making any reference to such properties. Such claims are considered in law to be "medicinal claims" and the prohibition is absolute, regardless of whether the substance of the claim is true.

Patrick Coppens, Nutritionist, Marlene Bijlsma, Dietician, LL.M., The Netherlands, Neville Craddock, M.A., F.I.F.S.T, United Kingdom, Inneke Herreman, LL.M., Belgium, Eva Hurt, M.A., United Kingdom, Yves Le BailCollet, DVM, LL.M., France, Peter Loosen, Lawyer, LL.M., Germany.

This article expresses the views of the authors and does not necessarily represent the policies of their employers. The authors are members of the "Health Claims" Expert Group of the Confederation of the Food and Drink Industries (CIAA)

Correspondence: Patrick Coppens, Rijksweg 64, B-2880 Bornem, Belgium. E-mail: patrick.coppens@nutricia.be
This absolute prohibition is founded on the state of scientific knowledge at the time of the formulation of the original Directive $79 / 112$, over 20 years ago. Since then scientific knowledge of the relationship between diet and health has advanced considerably.

Directive 65/65 (8) subjects all "medicinal products" (as defined) to a separate regulatory framework. On a literal interpretation of the existing legal texts, any food carrying a medicinal claim would become subject to medicinal legal procedures and would require a Product Licence.

The current debate on "health claims" on foods illustrates very clearly, however, the difficulty of defining what constitutes a preventive, therapeutic or curative claim (i.e. a "medicinal claim"). It is very difficult to refer to beneficial health effects or disease risk reduction without a reference to disease related topics (e.g. organs, physical conditions, symptoms, and even specific diseases). Such claims therefore have to be worded very carefully indeed if they are not to be considered as direct or implied medicinal claims.

A new concept of "Disease Risk Reduction" - separate from "preventive" claims - has therefore been proposed by ILSI (3) and Codex Alimentarius (9) amongst others, relating to the role that foods and food components can play in helping an individual to avoid specific diseases.

Health Claims can be classified as "Enhanced Function" or "Disease Risk Reduction" Claims. However, these concepts are not recognised in current European legislation.

- "Health Claims" are considered to be those claims establishing a relation between a food or a constituent of that food and health, whether it is good health or a condition related to health or disease.

- "Enhanced Function Claims" concern specific beneficial effects of nutrients and non-nutrients on physiological and 
psychological functions or biological activities beyond their established role in growth, development and other normal functions of the body.

- "Reduction of Disease Risk Claims" are those made for reduction of disease risk related to the consumption of a food or food component that might help reduce the risk of a specific disease or condition because of specific nutrients or non-nutrients contained within it.

In current European legislation, the most important problem is the lack of appropriate, universal definitions. Furthermore, in the absence of EU-wide legal definitions of such terms as "food", "prevention", and "disease", semantics and literal interpretations of legal texts may prevail in some Member States whereas, in others, an approach based on the perceived "spirit" of the legislation is applied. Whilst this reflects the differing legal systems in the Member States, it leads to legal uncertainty, characterised by inconsistent and arbitrary interpretation, as illustrated by case law at national and European level. The major discrepancies within and between Member States seem to arise from two crucial points.

Firstly, in the absence of a legal definition of "food" at the EU level, the definition of a "medicinal product" can be interpreted very broadly and differently between the Member States.

Secondly, in the parallel absence of clear definitions of "prevention" and "disease", Member States have been free to interpret the current EU prohibition on making preventive, therapeutic and curative claims for foods on the basis of a long history of national tradition.

\section{"Food" in the light of the EU definition of "medicinal product"}

The current EU definition of a "medicinal product" was introduced in Directive 65/65, back in 1965. This was only twelve years after Watson and Crick discovered the structure of DNA, four years before man walked on the moon, and in an era that could never have foreseen the revolution in the medical and nutritional sciences of the next thirty years.

Principal objectives of this Directive were to permit the free movement of medicinal products by partial harmonisation of National legislation and to protect public health by establishing a licensing system. The careful assessment of safety, quality and efficacy could allow efficient and safe medicines to be marketed, while products with unsubstantiated effects could be banned.

Directive 65/65 does not differentiate between medicinal products, cosmetics and food. Although the third Recital states an intention to exclude from its scope "substances or combinations of substances which are foods, animal feeding-stuffs or toilet preparations", foods were neither precisely defined nor specifically excluded by any formal Article. This is in contrast to the USA where 'Drug' is defined as "... article (other than food) intended to affect the structure or any function of the body..." Nevertheless, over the years, the definition of "medicinal product" contained in the Directive has been used frequently to judge specifically this difference.

The definition was established on a broad basis to encompass all products designed or claiming to deliver a preventive, therapeutic or curative effect, including not only products having a genuine effect but also those which are not sufficiently effective or do not have the effect which consumers might expect from their presentation. By submitting all products with medicinal claims to a common licensing procedure, it was considered that effective and consistent consumer protection could be ensured, not only from harmful or toxic products as such, but also from a variety of products being used instead of proper, effective remedies (10).
- The first subparagraph of article 1(2) of Directive 65/65 defines a "medicinal product" as "any substance or combination of substances presented for treating or preventing disease in human beings or animals".

- The second subparagraph of article 1(2) states that "any substance or combination of substances which may be administered to human beings or animals with a view to making a medical diagnosis or to restoring, correcting or modifying physiological functions in human beings or animals" is likewise to be considered a "medicinal product".

The Directive therefore gives two parts to the definition of a medicinal product, by virtue of its "presentation" and by virtue of its "functions". Consequently, a product is legally a "medicinal product" if it falls within either or both of these parts. This principle has been consistently held and confirmed by the European Court of Justice (ECJ) (11).

This broad definition of a "medicinal product" and the lack of an EU definition of "food" introduce three key questions:

\section{Are foods to be considered as medicinal products when carrying a medicinal claim?}

Article 2.1(b) of Directive 2000/13 and Article 6.1 of Directive $89 / 398$ (12) prohibit any explicit or implied reference to the property of preventing, treating or curing a human disease in the labelling, advertising or presentation of a food. Directive 80/777 (13) on Natural Mineral Waters similarly prohibits all such indications but, inconsistent with other legislation, allows Member States to authorise specific claims that could otherwise be considered as medicinal.

Foods and medicines have distinct, separate and mutually exclusive legislation. Any product intended for human consumption has to be treated either as a food or a medicinal product - it cannot, in law, be both. A "medicinal claim" may only lawfully be made in relation to a licensed medicinal product, and then only within the terms of the product licence. The prohibition, under food legislation, on making "medicinal claims" is absolute, regardless of the scientific accuracy of the claim itself.

The legal consequence of not specifically excluding foods from the scope of medicines legislation is that any traditional foods and food supplements might be considered as medicines when they make a medicinal claim. In the Ter Voort case (14), the ECJ ruled that: "A product which is recommended or described as having preventative or curative properties is a medicinal product [...] even if it is generally considered as a foodstuff and even if it has no known therapeutic effects in the present state of scientific knowledge". In the Delattre case (15), the Court affirmed that: "Even if a product comes within the definition contained in Article 1(1) of the (Cosmetics Directive) [...] a product must nevertheless be treated as a medicinal product and be made subject to the corresponding rules if it is presented as possessing properties for the treatment or prevention of illness or disease or if it is intended to be administered with a view to restoring, correcting or modifying physiologic functions." The decision will be based purely on the claim made, irrespective of whether, or not, the claim is scientifically valid or whether the product is effective.

\section{Could foods be considered as medicinal products} based on their physiological or other effects?

Directive 65/65 states that any "substance or combination of substances" that may be administered with a view to restoring, correcting or modifying physiological functions, is considered as a medicinal product.

"Administered" will normally imply some action by a third 
party, although the concept of self-medication also exists. It is generally more restrictive than "ingested" and allows a distinction between the application of a substance for "medicinal purposes" and the more general consumption of foods.

The use of the term "may be...." rather than "to be...." introduces an immediate ambiguity and uncertainty by allowing applications of a substance other than by "administration" (in its strict sense) also to result in it being regarded as a medicinal product.

The reference to "modifying physiological functions" is also capable of very broad interpretation. This concept was originally included largely to cover oral contraceptives, a group of products that had only recently appeared on the market, but did not fit the first definition, since they did not prevent, treat or cure a disease but modified a normal physiological function. Broadening the concept to other "physiological functions", such as digestion, respiration, excretion etc., as the Courts have been obliged to do, leads to numerous anomalies in the light of current scientific knowledge.

It has long been recognised that certain foods are able to restore and correct disturbed physiological functions caused by nutrient deficiencies (e.g. vitamin $\mathrm{C}$ rich foods will cure scurvy; iodised salt will restore thyroid function; vitamin A rich foods will restore night vision). Recent scientific literature amply and increasingly indicates that many other foods are able to restore, correct or modify physiological functions by virtue of the nonnutrient substances they contain (1). The very fact that foods are digested and the resulting nutrients metabolised or used as cofactors for enzymes, etc is evidence of such properties.

It must therefore be concluded that, in law, all foods can be considered medicinal products, if ingested with the view to restoring, correcting or modifying physiological functions. It is noteworthy that the Advocate General's Opinion (16) in the Delattre Case states that

"the second definition is formulated in such broad terms that, if read literally, it can apply both to medicinal products and foods".

In its judgement in this case (15), the ECJ deliberately combined the two definitions of a medicinal product, by cross-linking 'presentation' (in the definition only associated with "treatment or prevention" of human diseases) to 'restoration, correction or modification of physiological functions' (in the definition associated with "administration with a view to..."). It ruled that the two definitions cannot be regarded as strictly distinct from each other, since a substance that is endowed with 'properties for treating or preventing disease' within the meaning of the first definition of a medicinal product, but which is not "presented" as such, falls within the scope of the second definition, leaving no room for other possibilities. That is to say, claiming physiological effects can trigger medicinal status. As a consequence, the scope of the definition of a medicinal product is broadened even further than may originally have been intended.

\section{Could the composition of a food exclude}

\section{it from the definition of medicinal products?}

Directive 65/65 refers to medicinal products (Art. 1, 3) as "substances or a combination of substances...". Within the Directive itself, "substance" is defined as "any matter irrespective of origin which may be...human, animal, vegetable or chemical..."

Foods are "substances or combination of substances" within this broad definition. Therefore, the origin of the raw materials cannot, independently from the purpose they serve or from their impact on physiological functions, determine whether the product should be classified as a food or a medicine.

\section{Legal uncertainty \\ ECJ Jurisprudence}

Over the years, the legal uncertainties have led to serious problems. In some instances National Courts have sought clarification on the distinction between "food" and "medicinal product" from the ECJ, which has handed down judgements, derived directly from the definitions in Directive 65/65.

Firstly, the ECJ has ruled that it is the competence of Member States' National Authorities to judge whether a product is a medicinal product (17), stating in its judgement:
"At the present stage in the harmonisation of national rules on the production and distribution of pharma- ceutical products, it is for the national authorities to determine, subject to review by the courts, for each product, having regard to all of its characteristics, ..., whether or not it constitutes a medicinal product within the meaning of the definition set out in Article 1(2) of Directive 65/65".

The practical consequence is that there cannot be legal certainty at a European level as to the status of any given product, which the ECJ acknowledged could be considered as a food in one Member State, but as a medicinal product in another (14). Such judgement may be based on the specific characteristics of the product, examined against the European definition of medicinal products, or against a broader national definition. In this respect, in the absence of clear legal definitions to determine what qualifies products as foods or medicinal products, the Courts have developed a set of general criteria that, in practice, give unpredictable results.

Secondly, the ECJ has ruled that a product does not necessarily need to be presented explicitly for the prevention or treatment of human diseases to trigger medicinal status (18). A medicinal status may arise from the impression that an average, wellinformed consumer would be likely to gain. This may derive from aspects such as the product's composition, pharmacological properties, claims and associated commercial and noncommercial communication, its presentation (including any similarity to medicinal products) and point of sale, any risks arising from prolonged consumption, the way it is used, and its familiarity to the consumer.

Although all these aspects will be taken into consideration by the Courts, there is currently no systematic mechanism on the basis of Directive 65/65 whereby a product generally regarded as a food, but bearing disease or health related claims, can be excluded from the legal scope of "medicinal products". Because of the very broad definition, the Courts have no alternative but to conclude that a food, even with no known therapeutic effect, must still be considered a medicinal product, if presented for sale with such claims. As affirmed by the ECJ in the Ter Voort Case (14), (a case on herbal teas),

\section{"A product recommended or described as having prophylactic or therapeutic properties is a medicinal product "by virtue of its presentation" within the meaning of the first paragraph of Article 1(2) of Directive 65/65/EEC [...] even if it is generally regard- ed as a food and even if in the current state of scientific knowledge it has no known therapeutic effect".}

The question whether or not a product is perceived as "medicinal" will be resolved, primarily, by reference to the balance of medical and non-medical "uses" on the label or advertising and not to the likelihood of sales for one "use" rather than another. The nature of its constituents is not usually the decisive factor, although if a product contains therapeutic levels of pharmaco- 
logically active substances, this could well result in it being considered a medicine, even if the base-line product is clearly a food.

However, it is ultimately for the Court to balance its decision between the general notion that foods as such are excluded from the scope of the Directive, whereas products making a medicinal claim and/or having a medicinal effect are not. In reality, it is unlikely that any well-established food products or medicines would ever be considered as anything other than foods or medicines, respectively.

The difficulty of drawing the distinction in the grey area between clearly recognisable, conventional products and the growing generation of products possessing clearly established physiological properties urgently requires updated, legal clarification.

\section{National remedies}

Despite the ECJ judgements, it is clear that several Member States have adopted a pragmatic approach and attempted to distinguish foods from medicinal products with initiatives, some of which do not accord with European legislation. It is felt that foods are foods and should not become medicines simply on the basis of any claim made about them or their compositional characteristics.

However, even where Member States have introduced legal definitions of "food", these do not fully resolve the problem. This approach is easy to hold for ordinary foods but becomes more difficult for products in the grey area between normal foods and medicines, such as some foods bearing "health claims" and others, such as nutritional supplements, herbal preparations, and even dietetic foods.

The most obvious initiative is the creation of separate legal frameworks for such specific products and the introduction of registration, notification or authorisation procedures, to exempt them specifically from the field of medicinal products.

Another initiative is the drawing up of guidelines, Codes of Practice, clarification papers, etc. on the distinction between food and medicinal products, and on the substantiation and use of health claims, both by national authorities (19-22) and by others (23-29) in United Kingdom, Belgium, France, Finland, Sweden, The Netherlands and Spain.

In some countries, lists have been compiled with defined wording for claims that are considered medicinal and others that are not. Logically, some codes on good advertising practices also address this problem in the context of misleading advertising.

It is beyond the scope of this paper to elaborate and analyse the national differences in this respect. However, such initiatives ultimately lead to divergent and inconsistent interpretations and enforcement of the European legal provisions and, potentially, a different status for a given product between Member States.

A precise, EU-wide wide definition of "food", independent of that of "medicinal product" is therefore a first essential requirement.

\section{Distinctions between disease claims}

\section{The definition of disease}

Directive 65/65 specifies that a medicinal product is one presented for treating or preventing human diseases but fails, fundamentally, to define "disease". This problem has been acknowledged by the ECJ, which argued that the only possible interpretations of these terms are those most commonly accepted on the basis of scientific knowledge: "It is for the national authorities to determine whether products presented as counteracting certain conditions or sensations, such as hunger, heaviness in the legs, tiredness or itching, constitute a medicinal product (17)."
Where EU Member States have introduced national definitions of "disease", they are remarkably similar to each other and reflect the broad concept of "....including any injury, ailment or adverse condition of body or mind", but there is a definite trend to enlarge the scope to concepts formerly only considered as symptoms, such as high blood pressure and high cholesterol.

\section{The classical definition of disease prevention}

Directive 65/65 also fails to define "preventing" or "treating". Prior to 1965, "prevention" had only been used in its medical form. Vaccines had been shown to prevent infectious diseases effectively; many medicines effectively prevented complications of certain diseases and others effectively prevented sequels of a disease. The notion that many chronic diseases, such as cardiovascular disease, cancer, osteoporosis and diabetes were at least in part mediated by behavioural factors (e.g. eating habits, smoking, physical activity, etc) was largely unrecognised.

The verb "to prevent" can be defined as "to preclude, stop, keep, hinder, impede, to keep from coming to pass" and the noun "prevention" as: "the act of preventing: anticipation or forethought, obstruction" (30). Whilst the normal usage of "prevention" is to indicate an absolute action, its use in the sense of hindering or impeding does not. Similarly, the concepts of an obstruction or obstacle indicate a non-absolute barrier. Notwithstanding this non-absolute interpretation of the term, there will be situations where "reduction of risk" and "prevention" may be considered by some to be synonymous. For example, a "reduction of risk" in relation to Coronary Heart Disease is likely to be taken by an individual to infer that they will not suffer from a heart attack, i.e. "prevention".

In medicine, the use of the term "prevention" is normally taken to embrace the concept that preventive therapy will produce a result with a substantial degree of statistical certainty, whereas "Disease Risk Reduction" claims are generally based on epidemiological evidence gained from population based studies.

Thus, three types of "prevention" have been recognised (31) Examination of these also indicates that the concept of "prevention" should not be regarded as absolute:

"Type I: Prevention of disease occurrence"

Key characteristics are:

- The disease is not (yet) present.

- The therapy can prevent the occurrence of the disease with a substantial statistical certainty.

This represents the absolute sense of "prevention" (e.g. the purpose of many vaccines).

"Type II: Prevention of episodes of the disease"

Key characteristics are:

- The disease is present.

- The therapy decreases the number, duration, or severity of disease episodes with a substantial statistical certainty.

This represents a reduction in severity, since the underlying disease remains. It is exemplified by medicines given to patients with chronic diseases (e.g. asthma, epilepsy) and should more correctly be considered as part of the management of an existing disease, rather than "prevention" in the absolute sense.

"Type III: Prevention of progression of the patient's underlying disease"

Key characteristics are:

- The disease is present.

- The therapy has been shown to delay the progression of the disease with a substantial statistical certainty.

Medicines are given to prevent the more serious sequels of a disease and to hinder its progression rather than to 
"prevent" it absolutely. Examples include patients who are either asymptomatic (e.g. lowering blood pressure in hypertensive patients, or decreasing lipids in hyperlipidemias) or symptomatic (e.g. decreasing blood sugar in diabetic patients, or treating mildly and moderately symptomatic patients who are HIV-positive to slow the progression of AIDS).

It is now accepted that certain types of foods may contribute towards both type II and type III treatments. These "foods for special medical purposes" are suitable for the dietary management of the particular disease and are regulated at the European level through Directive 1999/21 (32)

\section{The concept of disease risk reduction}

Reduction of Disease-Risk Claims are defined as claims made for reduction of disease risk related to the consumption of a food or food component that might help reduce the risk of a specific disease or condition because of specific nutrients or nonnutrients contained within it (3).

Since the 1970's, it has been clear that many chronic diseases, such as cardiovascular diseases, cancer and osteoporosis are at least partially mediated by behavioural factors such as diet, smoking and physical activity. More recently, strong scientific evidence is increasingly showing that a wider range of modifications to the diet can make significant contributions towards reducing an individual's risk of getting a particular disease, although such changes cannot with substantial statistical certainty guarantee that the disease will not occur. Other behavioural measures, such as taking physical exercise and stopping smoking, environmental factors (exposure to pollution, etc) and genetic constitution may play an equal, if not more important, role in the reduction of an individual's risk.

These measures relate to the exposure to diseases risk factors when "prevention" relates to the incidence (Type I, Type II) or to the evolution (Type III) of diseases. Therefore, in order to address such measures, the new concept of "disease risk reduction" has been proposed:

Key characteristics are:

- The disease is not present.

- The cause of the disease is multi-factorial, including dietary, behavioural, environmental, and genetic factors.

- Modification of certain dietary components, alone, cannot ensure that the disease will not develop, since it does not affect the other factors but, nevertheless, it may help significantly to reduce the likelihood of getting the disease.

In the current European legal framework for foods and medicines, and without an accepted definition of "prevention", "disease risk reduction" could be considered "prevention". But the terms are not synonymous. If, for instance a person stops smoking and it is asked if this would reduce his risk of getting lung cancer, the answer will of course be 'yes'. But if asked if this would prevent the development of lung cancer, most would argue 'no', because there are many other factors influencing the development of lung cancer. "Disease risk reduction" measures should therefore be considered as "health-promoting", rather than "disease-preventing".

Once the scientific validity of a link between a dietary component and a disease has been established, "disease risk reduction" claims should be permitted by European food labelling and advertising legislation to express clearly, and more directly, the beneficial relationship between a food or its components and human health. This would require a modification of the labelling Directive 2000/13, in order to establish, uniformly at the European level that the concept of "disease risk reduction" is valid for foods and inherently different from the concept of "prevention" in the absolute sense. The latter is a medical concept and should continue to be regulated under medicinal product legislation.

\section{Future developments}

\section{A definition of "food"}

The distinction between foods and medicinal products can only be clarified if a precise, EU-wide definition of "food" is developed, independent of the definition of a "medicinal product", to ensure that only these two categories co-exist in a legally coherent and reasonable framework. The definition of "food", as included in the recent proposal for a general food law regulation (33), however, has clearly not been developed with this problem in mind, since it simply excludes "medicinal products" within the meaning of Council Directive 65/65 from the scope of "food". By linking back to the definition of "medicinal product", the proposal does not therefore give additional clarification but instead completely fails to address the problems outlined in this paper and may even create further inconsistency.

\section{A definition of "medicinal product"}

The definition of "medicinal product" is itself the subject of revision (34). The European Commission is proposing to replace the word "administered" by "used" in the second part of the definition. While "administered" would in certain cases restrict the scope of the definition, this will clearly not be the case if it is replaced with "used".

Further, the definition of "medicinal product" would be widened considerably by the proposal that Directive 65/65

\section{"shall apply whenever a substance or combination of substances falls within the definition of medicinal product at Article 1 (1), even in cases where the sub- stance or combination of substances falls also within the field of application of other Community legislation".}

This would further undermine legal certainty and increase confusion regarding the distinction between foods and medicinal products.

\section{Health claims}

It was rather disappointing that in its White Paper (35), the European Commission declared that labelling and advertising of a food should not contain 'health claims'. The European Commission is currently prepared only to consider specific provisions to govern 'nutrition and function' claims, as reflected in the recent discussion paper on claims (36), on which all stakeholders have been invited to comment.

\section{Conclusions}

- Progress in nutritional sciences has led to the recognition of the beneficial role of food and food constituents in the promotion of health and the reduction of the risk of chronic diseases and has led to the development of a new generation of food products possessing well-established physiological properties.

- Consumers' growing interest in the health and nutritional benefits of foods can only be satisfied by the communication of appropriate, factual information. Most importantly, if the results of scientific research into the relationship between foods and health cannot be communicated effectively, there is a real risk that the financial support for this important research will no longer be forthcoming. 
This has led several international bodies to propose definitions and criteria for health claims, including "disease risk reduction" claims.

- The main problem is that these definitions are not recognised in current EU legislation. Directive 2000/13 prohibits, absolutely, attributing to foods any properties relating to the prevention, treatment and cure of human diseases. On the other hand, the definition of medicinal products is interpreted so broadly that food products making health claims may fall under it.

- The increasing difficulty of distinguishing between conventional foods and medicines, and determining the legal status of the new generation of food products possessing wellestablished physiological properties urgently requires updated, legal clarification. However, it is the legislation that should be amended, rather than the status of the product itself.

- In the absence of a precise EU-wide legal definition of "food", that is independent of the very broad definition of "medicinal product", there is a danger that the latter will increasingly be used to resolve the boundary between them. This would contradict the principle that products that are placed on the

\section{REFERENCES}

1. Bellisle F. et al: Functional Food Science in Europe, Br J Nutr 1998;80 Suppl. 1:S3-S193.

2. Knorr D. et al: Functional Food Science in Europe, Trends Food Sci Technol 1998;9:293-344.

3. Diplock A. et al: Scientific Concepts of Functional Foods in Europe: Consensus Document, Br J Nutr 1999;81 Suppl 1:S1-S27.

4. Food and Drug Administration: US Guidance for Industry: Significant scientific agreement in the review of health claims for conventional foods and dietary supplements. 1999.

http://vm.cfsan.fda.gov/ dms/ssaguide.html

5. Council of Europe; Council of Europe's policy statements concerning nutrition, food safety and consumer health: Guidelines concerning scientific substantiation of health-related claims for functional Food; Technical Document. 2001. http://www.coe.fr/soc-sp/sante/funct\%20food.htm

6. Codex Alimentarius Committee on Nutrition and Foods for Special Dietary Uses; Discussion Paper on the Scientific Criteria for Health Claims; CX/ NFSDU/ 00/10. April 2000.

ftp://ftp.fao.org/codex/ccnfsdu22/nf00_10e.pdf

7. Directive 2000/13/EC of the European Parliament and of the Council of 20 March 2000 on the approximation of the laws of the Member States relating to the labelling, presentation and advertising of foodstuffs (Formerly Council Directive 79/112/EEC of 18. December 1978. http://europe.eu.int/ eur-lex/en/consleg/pdf/2000/en_2000L0013_do_001.pdf

8. Council Directive $65 / 65 / \mathrm{EEC}$ of 26 January $\overline{1} 96 \overline{5}$ on the approximation of provisions laid down by Law, Regulation or Administrative Action relating to proprietary medicinal products. http://europe.eu.int/eur-lex/en/lif/dat/1965/en 365L0065.html

9. Codex Alimentarius Committee on Food Labelling; Alinorm 01/22 (Appendix VIII), currently at step 3 of the Procedure (2001). $\mathrm{ftp}: / / \mathrm{ftp}$.fao.org/codex/ALINORM01/A101_22e.pdf

10. Case C-112/89, Judgement of the Court of $1 \overline{6}$ April 1991, Upjohn Company and Upjohn NV v Farzoo Inc. And J. Kortmann, European Court Reports $1991 ; \mathrm{I}: 1703$

11. Case C-60/89, Judgement of the Court of 21 March 1991, Criminal proceedings against Jean Monteil and Daniel Samanni, European Court Reports 1991;I: 1547.

12. Council Directive 89/398/EEC of 03 May 1989 on the approximation of the laws of the Member States relating to foodstuffs intended for particular nutritional uses. http://europe.eu.int/eur-lex/en/consleg/pdf/1989/en_ 1989L0398_do_001.pdf

13. Council Directive $80 / 777 / \mathrm{EEC}$ of 15 July 1980 on the approximation of the laws of the Member States relating to the exploitation and marketing of natural mineral waters. http://europe.eu.int/eur-lex/en/consleg/pdf/1980/ en_1980L0777_do_001.pdf

14. Case C219-91, judgement of the Court of 28 October 1992, Criminal proceedings against Johannes Stephanus Wilhelmus Ter Voort, European Court Reports 1992;I:5485.

15. Case C369-88, judgement of the Court of 21 March 1991, Criminal proceedings against Jean-Marie Delattre, European Court Reports 1991;I: 1487.

16. Case C-369/88: Opinion of Mr. Advocate General Tesauro delivered on 16 January 1991. Criminal Proceedings against Jean-Marie Delattre, European Court Reports 1991;I: 1487.

17. Case C-290/90, judgement of the Court of 20 May 1992, Commission of the European Communities v Federal Republic of Germany; European Court market and commonly regarded as foods should be and remain subject to food legislation only.

- The second problem is the interpretation that "risk reduction" is synonymous with "prevention", making the communication of such claims illegal under current food law. A practical and legitimate solution would be to allow validated "disease risk reduction" claims for foods by excluding such claims from the scope of "prevention" in its medical sense. This would require a modification of Directive 2000/13. Possible mechanisms for the development of, and conditions that would apply to, health claims for foods have been developed by CIAA and in voluntary codes at both national and international levels.

- The recently proposed changes to the definition of medicinal products and the proposed definition of foodstuffs in the general food law regulation indicate that it is not a priority for the European Commission to provide clarity on the distinction between foods bearing health claims and medicinal products, nor to develop a legal framework for health claims on foodstuffs.

Reports, 1992;I:3317.

18. Case C227-82, judgement of the Court of 30 November 1983, Criminal proceedings against Leendert van Bennekom, European Court Reports $1983 ; 3883$.

19. UK: Medicines Control Agency: A Guide to what is a Medicinal Product, MCA Guidance Note No 8. Previously MAL 8. 2000. http://www.mca.gov.uk/inforesources/publications/gn8.pdf

20. B: Ministeriële Circulaire betreffende artikel 1 van de wet van 25 maart 1964 op de geneesmiddelen, 1987.

21. Fr: Conseil National de l'Alimentation, Allégations faisant un lien entre alimentation et santé. 1998 . http://www.finances.gouv.fr/reglementation/avis/cna/avis063098.htm

22. F: National Food Administration, Medicinal and Health Claims in the Marketing of Foodstuffs.1997.

23. UK: Joint Health Claims Initiative. 2000 http://www.jhci.org.uk/code.pdf

24. Belgium: Federatie Voedingsindustrie, Code of Conduct Gezondheidsbeweringen. 2000.

25. Sweden: Swedish Nutrition Foundation, Health Claims in the Labelling and Marketing of Food Products, a Self-Regulating Programme. 1997. http://www.snf.ideon.se/snf/en/rh/index.htm

26. The Netherlands: Voedingscentrum, Gedragscode Wetenschappelijke Onderbouwing Gezondheidseffecten ten behoeve van Gezondheidsclaims voor eet- en drinkwaren. 1998.

http://www.voedingscentrum.org/gedra_en.html

27. The Netherlands: Keuringsraad Aanprijzing Gezondheidsproducten, Code voor Aanprijzing van Gezondheidsproducten (KAG. 2001. http://www.koagkag.nl/leidraad/cagindex.html

28. Spain: Ministerio de Sanidad y Consumo - Federación Española de Industrias de la Alimentación Bebidas, Acuerdo Interpretativo sobre la Publicidad de las Propriedades de los Alimentos en Relación con la Salud 1998.

29. European Food Federation (CIAA): Code of Practice on the use of health claims. 2000. http://www.ciaa.be/en/Documents/positions/ scientreg/MIN06699EF.html

30. Kirk E.M. Chambers 20th Century Dictionary. 1987.

31. Spilker B., Guide to Clinical Trials, p. 160, Raven Press (1991), ISBN: 0-88167-767-1.

32. Commission Directive 1999/21/EC of 25 March 1999 on dietary foods for special medical purposes. http://europe.eu.int/eur-lex/en/consleg/pdf/ 1999/en_1999L0021_do_001.pdf

33. Amended proposal for a regulation of the European Parliament and of the Council laying down the general principles and requirements of food law, establishing the European Food Authority, and laying down procedures in matters of food (COM (2001) 475 final; 07/08/2001). http://europe.eu.int/comm/food/fs/intro/efa_prop2_en.pdf

34. Proposal for a Directive on the Community code relating to medicinal products for human use (as adopted by the Commission on the $18 / 07 / 2001$ ). http://pharmacos.eudra.org/F2/review/doc/2 codehumain_fr_18-72001.pdf

35. White paper on food safety (COM (1999) 719 final; 12/01/2000). http://europe.eu.int/comm/dgs/health_consumer/library/pub/ pub06_en.pdf

36. Discussion paper on nutrition claims and functional claims.SANCO/1341/ 2001. http://europe.eu.int/comm/food/fs/fl/fl03 en.pdf 